\title{
The Effects of Attachment to Korean Wave Stars and Cultural Proximity on Chinese Consumers' Purchase Intention of Korean Products
}

\author{
Garog Han ${ }^{1}$, Jungmin Park ${ }^{2}$, Jae-Eun Lee ${ }^{1}$
}

${ }^{1}$ Sunchon National University, Suncheon, Korea

${ }^{2}$ University of Ulsan, Ulsan, Korea

Objectives: The majority of prior studies have identified attachment to Korean Wave stars and cultural proximity as important determinants in the purchase intention of Korean products, but no comprehensive study considering these two factors at the same time has been conducted. Therefore, in order to overcome the limitations of previous studies, this study conducts a comprehensive study to investigate the effect of attachment to Korean Wave and cultural proximity (psychological and experiential proximity) on purchase intention of Korean products.

Methods: To collect research data, a survey of Chinese consumers was conducted for about two months from October to December 2020. As a result of the survey, 384 questionnaires were collected, of which 240 questionnaires were finally used to perform regression analysis, excluding 144 questionnaires that were judged to be difficult to use for analysis.

Results: As a result of the empirical analysis of Chinese consumers, it was found that both attachment to Korean Wave stars and cultural proximity (psychological and experiential proximity) had a significant positive effect on purchase intention of Korean products.

Conclusions: The results of this study suggest that the attachment to Korean Wave stars and psychological and experiential cultural proximity are important antecedents of the purchase intention of Korean products. These findings will be able to provide meaningful practical implications for Korean companies that need to formulate and implement marketing strategies for Chinese consumers.

Key Words: Korean Wave, Purchase Intention, Psychological Cultural Proximity, Experiential Cultural Proximity, Chinese Consumers

Received: Sep 25, 2021 Revised: Nov 25, 2021 Accepted: Nov 30, 2021

Corresponding author: Jae-Eun Lee

Department of International Trade, Sunchon National University, 255, Jungang-ro, Suncheon 57922, Korea

Tel: +82-61-750-3726, E-mail: sky2u@scnu.ac.kr

This is an Open Access article distributed under the terms of the Creative Commons Attribution Non-Commercial License (http://creativecommons.org/licenses/ by-nc/4.0/) which permits unrestricted non-commercial use, distribution, and reproduction in any medium, provided the original work is properly cited.

Copyright $(9) 2022$ Korean Association for Business Communication.

\section{Introduction}

Recently, the Korean wave has produced cultural content that is loved around the world (Kim \& Park, 2020). The movie Parasite becoming the first Korean film to win best international feature film, best original screenplay, best director, and best picture at the 2020 Academy Awards, and Squid Game topped the world's preference and viewing rankings on Netflix, a famous OTT (over the top) service in 2021. In addition, the Korean boy group BTS topped the U.S. Billboard chart with a song called "Dynamite," while the girl group BLACKPINK topped the world with the 
number of YouTube followers. As such, the global craze for the Korean Wave is getting stronger, and Korea's image is also becoming more positive due to the Korean Wave (Wakefield \& Blodgett, 1999; Yang \& Lee, 2020).

China in particular has been particularly affected by the Korean Wave and is a major consumer of Korean Wave content and Korean products (Yang \& Lee, 2020). Therefore, many scholars have conducted research on the effect of Korean Wave on the purchase intention of Korean products for Chinese consumers (Bae \& Lee, 2018; Jang \& Kim, 2018; Kim \& Park, 2020; Yang, Jin, \& Jung, 2020). However, Netflix, one of the distribution channels of Korean Wave content, is not officially providing services in China, and the Chinese government is increasing regulations to curb the consumption of Korean Wave content. Although it is difficult for Korean Wave content to be distributed normally in the Chinese market, Chinese consumption of Korean Wave content is increasing (Zhou \& Lee, 2021). In particular, at the center of the growing number of Korean Wave is the Korean Wave Star, a symbol of Korean Wave content.

Korean Wave stars play an important communication role between consumers and advertisers, but research focusing on Korean Wave stars has been lacking. Most of the preceding studies that investigated the relationship between Korean Wave stars and purchase intentions of Korean products consider Korean Wave stars to be human brands. Therefore, research has been conducted focusing on the attributes of human brands (Kim, Jun, Kim \& Han, 2010) and the characteristics of human brands (Hwang \& Park, 2021; Kim \& Lee, 2019). Lee and Jeong (2016) viewed Korean Wave stars as a kind of human brand and investigated the effect of attachment to Korean Wave stars on the relationship between Korean brand authenticity and trust. Therefore, the study by Lee and Jeong (2016) is clearly different from this study investigating the relationship between the attachment to Korean Wave stars and the purchase intention of Korean products (Shen \& Kim, 2018).

Meanwhile, previous studies focusing on cultural proximity have focused on the degree to which consumers respond differently depending on the degree to which cultures between a home country and host country are close and familiar $(\mathrm{Lu}$, Liu, \& Cheng, 2019; Ng, 2013). Many previous studies have regarded cultural proximity as an extended concept of cultural distance (Cyrus, 2012). Such studies use cultural proximity as a multidimensional concept that it is not geographically close, but psychologically and experientially close (Wang \& Lee, 2019; Zhang, Park, \& Lee, 2015). However, despite various preceding studies on cultural proximity, there is no comprehensive study examining the relationship between cultural proximity and purchase intention of Korean products in consideration of the attachment of Korean Wave stars at the same time. Therefore, in order to overcome the limitations of these previous studies, this study aims to investigate the effects of attachment to Korean Wave stars and cultural proximity on purchase intention of Korean products.

\section{Literature Review}

\section{Purchase Intention}

Purchase intention means withholding the purchase of a specific product rather than purchasing a specific product (Chang \& Wildt, 1994) and is used to understand the behavioral intention of consumers who make a purchase (Ajzen \& Fishbein, 1977; Vuong \& Giao, 2020). In particular, since purchase intention is a kind of decision-making to purchase a specific product (Shah et al., 2012), it tends to lead to a purchase in a short period of time (Mirabi, Akbariyeh, \& Tahmasebifard, 2015; Tjoe \& Kim, 2016). Many researchers pay attention to the Korean Wave as one of major determinants for purchase intention in that high purchase intention increases the possibility of leading to an actual purchase (Nann \& Park, 2016).

Previous studies that have investigated the relationship between Korean Wave content and the purchase intention of Korean products emphasize that the higher the consumption of Korean Wave content (e.g., K-pop, K-drama, K-food, K-fashion), the higher the purchase intention of Korean products (Lee, Kang, \& Lee, 2017; Shen \& Kim, 2018). For example, Tjoe and Kim (2016) emphasized that the Korean Wave has a positive effect on the intention to purchase Korean products by enhancing not only the country image but also the country of origin's image of Korea. Yang and Lee (2020) also investigated the relationship between satisfaction with Korean Wave content and the purchase intention of Korean products for 300 Chinese consumers. They argued that satisfaction for Korean Wave contents has a positive effect on the purchase intention of Korean products because it provides a positive country image of Korea and raises expectations for Korean products.

Augusta, Mardhiyah, and Widiastuti (2019) suggested that as a result of an empirical analysis of 213 Indonesian consumers, the country of origin image for Korea has a positive effect on the intention to purchase Korean products. Yu and Yu (2020) empirically analyzed the effect of fashion products advertised by Korean celebrities on the purchase intention of Korean products on Chinese consumers. As a result of the analysis, the authors argued that Korean celebrity play a role as brand ambassador for products that can increase product trustworthiness, attractiveness, and expertise, and increase congruency between celebrity and product, which can have a positive effect on Korean 
product purchase intention.

As such, many previous studies related to the Korean Wave emphasize that the Korean Wave is an important determinant of intention in purchasing Korean products, but comprehensive studies that simultaneously consider the attachment of Korean Wave stars and cultural proximity are still insufficient. In particular, considering that the Korean Wave has been loved for a long time, starting with the popularity of Korean dramas in the 1990s, the attachment to Korean Wave stars and psychological and experiential cultural proximity to Korea have increased even more than before (Lee \& Jeong, 2016; Wang \& Lee, 2019; Yang \& Lee, 2020; Zhang et al., 2015). Therefore, this study aims to investigate the relationship between the attachment to Korean Wave stars and psychological/experiential cultural proximity.

\section{Attachment to Korean Wave Starts and Purchase Intention of Korean Products}

Attachment to Korean Wave stars means that consumers have an emotional attachment and have formed a construct of ingroup ties like a psychological sense of community in a kind of "human brand" such as celebrities and sports stars that influence them (Jeong \& Lee, 2016; Obst \& White, 2005; Thomson, 2006). If the attachment to Korean Wave stars is high, consumers have a desire to have a close relationship by forming intimacy with the Korean Wave stars (Cole \& Leets, 1999). If a consumer has a high attachment to Korean Wave stars, the degree of attachment can also affect the consumer's purchasing behavior (Ilicic \& Webster, 2009; Jeong \& Lee, 2016). Therefore, many previous studies related to the attachment to Korean Wave stars have noted that consumer reactions vary depending on their attachment (Giles \& Maltby, 2004; Jeong \& Lee, 2016; Thomson, 2006).

Greenwood and Long (2011) conducted interpersonal ratings on 173 students and found that the intimacy felt with media figures was higher than that of friends living together in daily life. These results imply that individuals tend to identify themselves with media stars through emotional exchanges of media figures and that they try to feel stable by forming a strong psychological bond with media figures (Fournier, 1998; Thomson, Maclnnis, \& Park, 2005). In other words, the higher the attachment to Korean Wave stars, the more intimate they feel to Korean Wave stars, and consumers have the characteristic of equating themselves with Korean Wave stars through emotional exchanges. In particular, when consumers feel attached to Korean Wave stars, loyalty and reliability to Korean Wave stars increase (Ohanian, 1990), consumers may have a higher desire to own products consumed by Korean Wave stars (Lee \& Jeong, 2016; Thomson, 2006).
Malär, Krohmer, Hoyer, and Nyffenegger (2011) also argued that when consumers are attached to the human brand, they have the characteristic of emotionally identifying themselves with the brand (Kleine, Kleine, \& Kernan, 1993; Park, MacInnis, Priester, Eisingerich, \& Iacobucci, 2010), which increases their desire to purchase products that the human brand has or uses (Boldero \& Francis, 2002). Natalia and Rizan (2021) empirically analyzed the effect of celebrity endorser on consumers' purchase intentions for 210 Indonesian consumers. As a result, it was found that consumers' emotional attachment to celebrities had a positive effect on purchase intention. In other words, emotional attachment to celebrities has a positive effect on purchase intention because it forms a bond with the brand and increases brand loyalty (Kowalczyk \& Pounders, 2016).

In sum, an attachment to Korean Wave stars represents not only a high loyalty and reliability to Korean Wave stars but also a higher desire to emotionally identify with Korean Wave stars, so the higher the attachment to Korean Wave stars, the higher the intention to purchase Korean products.

- Hypothesis 1: Attachment to Korean Wave stars will have a positive effect on purchase intention of Korean products.

\section{Cultural Proximity and Purchase Intention of Korean}

Products

Cultural proximity is defined as the degree to which the cultures of the two countries or two regions are close (Straubhaar, 1991) and the degree to which they feel intimacy (Felbermayr \& Toubal, 2010). In other words, cultural proximity means that the total physical, emotional, affective, and cognitive characteristics of society and its members have similar values or forms of consciousness between countries or regions (Khan \& Rahman, 2014; Wang \& Lee, 2019).

Previous studies that studied cultural proximity regarded cultural proximity as a cultural distance (Cyrus, 2012) and argued that when the distance between countries or regions is close, a culture is close and people feel homogeneity and affinity toward close cultures (Felbermayr \& Toubal, 2010). However, due to the recent increase in individual overseas experiences such as overseas travel and studying abroad and the development of media, overseas content has become easier to access than in the past, allowing them to feel cultural proximity even if the distance between countries or regions is not close (Elasmar, 2014; Zhang et al., 2015). Additionally, with the development of OTT and social network service (SNS), access to overseas content has become easier, and communication methods with celebrities have diversified and become easier. As a result, consumers' affinity with celebrities has increased compared to the past, and they have become psychologically close to celebrities, increasing 
their desire to purchase products consumed by celebrities (Rabbanee, Roy, \& Spence, 2020).

Many previous studies conducted research by dividing cultural proximity into psychological cultural proximity and experiential cultural proximity (Wang \& Lee, 2019). Korea and China share relatively similar cultures as well as a geographically close distance from the other. In particular, many Chinese consumers are interested in content such as Korean dramas and movies, and many Chinese people have visited Korea or have studied there (Kim \& Ahn, 2012; Yang \& Lee, 2020). Therefore, in this study, the degree of experience such as visiting Korea, studying abroad in Korea, and the presence or absence of Korean friends is defined as experiential cultural proximity between China and Korea, and the degree of preference in Korean dramas and movies is defined as psychological cultural proximity between China and Korea (Wang \& Lee, 2019).

\section{Psychological Cultural Proximity and Purchase Intention of Korean Products}

Some previous studies emphasize that the psychological cultural proximity felt by consumers has a positive effect on the purchase intention of foreign products. For example, Wang and Lee (2019) empirically analyzed the effect of Chinese female consumers' psychological cultural proximity to Korea on the purchase intention of Korean fashion products, focusing on the degree of SNS utilization. As a result of the analysis, the authors suggested that the Korean culture experienced by Chinese consumers holders through SNS activities increases the positive image of Korean products and has a positive effect on the attitude toward Korean products (Wang \& Lee, 2019). This shows that psychologically closeness with Korean Culture through SNS (Mirabi et al., 2015) increases good feelings for Korean products, having a positive effect on the intention to purchase Korean products (Erdem \& Swift, 1998; Saleem, Ghafar, Ibrahim, Yousuf, \& Ahmed, 2015).

Lee and Lee (2012) investigated the relationship between the digital characteristics of SNS and the purchase intention of cultural content. Since various consumers participate in SNS, SNS not only provides users with opportunities to form psychological close relationships between participants and users, but also provides diverse information related to foreign products through real-time information exchanges between users, increasing the purchase intention of foreign products (Kim, Kireyeva, \& Youn, 2014; Lee \& Lee, 2012). In other words, the author emphasizes that SNS can quickly provide information on Korean products to consumers in a variety of ways and that it can increase the intention to purchase cultural content by forming an emotional attachment to Korea to SNS users (Lee \& Lee, 2012). Although the author did not directly mention psychological cultural proximity, SNS in his study can be seen as the main means of making Chinese consumers form psychological familiarity with Korea. In sum, if Chinese consumers have close psychological cultural proximity to Korea, the image of Korea and Korean products can also be positively formed, which will have a positive effect on the intention to purchase Korean products.

- Hypothesis 2: Psychological cultural proximity about Korea will have a positive effect on purchase intention of Korean products.

\section{Experiential Cultural Proximity and Purchase Intention of Korean Products}

Lee et al. (2017) empirically analyzed the effect of tangible and intangible Korean Wave experiences on the purchase intention of Korean products for Chinese consumers. As the result of their study, the authors found that satisfaction with the tangible Korean Wave experience forms a positive perception of Korea and acts as a halo effect, having a positive effect on the purchase intention of Korean products (Lee et al., 2017). In addition, the authors presented evidence that the continuous experience of intangible Korean content can have a positive effect on the intention to purchase Korean products because it can form a positive image of Korea and Korean products (Lee et al., 2017).

Khan and Rahman (2014) investigated the relationship between experiential marketing and customer purchase intention for 150 consumers in the automobile market. Since product experience allows consumers to feel and think about products (Taylor \& Baker, 1994), consumer experience marketing has a positive effect on product purchase intention (Khan \& Rahman, 2014). Nasermoadeli, Ling, and Maghnati (2013) also argued that emotional experience, which refers to the mood and emotions generated during a shopping trip, and social experience which refers to the relationship with others and society (Schmitt, 1999), had a positive effect on product purchase intention. Emotional and social experiences have positive effects on purchase intention because emotional experiences provide positive moods, joy, and satisfaction for the brand (Schmitt, 1999; Yang \& He, 2011), and social experiences can obtain useful experience about the brand through peer groups (Nasermoadeli et al., 2013).

In sum, various experiences with the product not only acquire useful information about the product but also form a positive perception, resulting in a halo effect related to the product. Therefore, experiential cultural proximity to Korea can have a positive effect on the intention to purchase Korean products because consumers can receive useful information on Korean products to form positive perceptions and have a halo effect on Korean products. 
- Hypothesis 3: Experiential cultural proximity about Korea will have a positive effect on purchase intention of Korean products.

\section{Methods}

\section{Data Collection}

In order to collect research data, a survey was conducted on Chinese consumers living in China. We translated the questionnaire into Chinese with the assistance of a native Chinese speaker and tried to reduce translation errors through the reverse translation process. The questionnaire was distributed to Chinese consumers through e-mail and a SNS from October to December 2020. As a result of the survey, 384 questionnaires were collected, of which 240 questionnaires were finally used to perform regression analysis, excluding 144 questionnaires that were judged to be too difficult to use for analysis.

\section{Measurement}

\section{Dependent Variable}

The dependent variable of this study is purchase intention of Korean products. Referring to the research of Wang and Yang (2010) and Yang and Lee (2020), we measured the purchase intention of Korean products based on how much respondents agreed to the following four questions. The specific questions are i) I think it is reasonable to purchase Korean products, ii) If I have an opportunity, I will buy Korean products, iii) I will purchase and use more Korean products in the future, iv) I will continue to purchase Korean products.

\section{Independent Variables}

The independent variables of this study are attachment to Korean Wave stars, psychological cultural proximity and experiential cultural proximity. First, referring to the research of Lee and Jeong (2016), we measured the attachment of Korean Wave stars based on how much respondents agreed to the following four questions. The specific questions are i) I feel close to Korean Wave stars, ii) I feel affection for Korean Wave stars, iii) If I can't see Korean Wave stars, I will miss them, iv) It would be sad if the Korean Wave stars disappear from my life.

Second, referring to the research of Wang and Lee (2019), Zhang et al. (2015), we measured the psychological cultural proximity based on how much respondents agreed to the following five questions. The specific questions are i) I'm interested in Korean celebrities, ii) I like Korean dramas and movies, iii) I like Korean culture, iv) I want to make Korean friends, v) I tend to enjoy Korean fashion styles.

Lastly, referring to the research of Wang and Lee (2019),
Zhang et al. (2015), we measured the experiential cultural proximity based on how much respondents agreed to the following five questions. The specific questions are i) I have visited Korea, ii) I have stayed in Korea, iii) I have many Korean friends, iv) I'm familiar with the lifestyle of Korea, v) I have experienced Korean art (theater, musical, dance, concert, exhibition, etc.).

\section{Control Variables}

In this study, the gender (male $=0$, female $=1$ ), age, and duration of stay (month) in Korea of Chinese consumers were considered as control variables.

\section{Results}

Table 1 presents the validity and reliability results of the variables used in this study.

First, we performed the Kaiser-Meyer-Olkin (KMO) test for sampling adequacy and Bartlett's test of sphericity. As a result of the analysis, the KMO value was .892, and the Chi-square and $\mathrm{p}$ value from Bartlett's test of sphericity was confirmed to be $3,126.761(p<.001)$. Therefore, it was confirmed that the data collected in this study were suitable for performing a factor analysis. Second, an exploratory factor analysis was conducted to analyze the validity of the variables used in this study, and a varimax rotation was used. As a result of the factor analysis, the factor loading values of each item were all .6 or more, confirming that there was no major problem with the validity of each variable. Third, Cronbach's alpha value was used to confirm the reliability of each variable, and as a result of the analysis, all of Cronbach's alpha values were confirmed to be .8 or higher, confirming that there was no problem with the reliability of the measurement variable (Nunnally, 1978).

Table 2 presents the results of correlation analysis with descriptive statistics of each variable used in this study.

We checked the Variance Inflation Factor (VIF) values and Condition Index (CI) values to confirm the possibility of multicollinearity. The maximum value of the VIF was 1.823 (average $=1.472$, minimum $=1.068$ ), which did not exceed the reference range of 10 , and the maximum value of the $\mathrm{CI}$ was also 14.219 (average $=7.485$, minimum $=1.000$ ), which did not exceed the reference range of 30 (Chatterjee \& Hadi, 2006; Hair, Anderson, Tatham, \& Black, 1998; Joseph, William, Barry, \& Rolph, 1998). Therefore, we judged that the problem of multicollinearity was not at a worrisome level.

The regression analysis results of this study are presented in Table 3.

Model 1 in Table 3 shows only the influence of control variables. As a result of the analysis, it was found that the period of 
Table 1. Results of validity and reliability tests

\begin{tabular}{|c|c|c|c|c|}
\hline Variable & Factor 1 & Factor 2 & Factor 3 & Factor 4 \\
\hline Experiential cultural proximity 1 & .891 & .171 & .088 & .187 \\
\hline Experiential cultural proximity 2 & .900 & .112 & .064 & .229 \\
\hline Experiential cultural proximity 3 & .796 & .259 & .210 & .042 \\
\hline Experiential cultural proximity 4 & .660 & .332 & .182 & .340 \\
\hline Experiential cultural proximity 5 & .678 & .256 & .087 & .294 \\
\hline Psychological cultural proximity 1 & .175 & .683 & .385 & .095 \\
\hline Psychological cultural proximity 2 & .201 & .790 & .208 & .168 \\
\hline Psychological cultural proximity 3 & .346 & .762 & .199 & .201 \\
\hline Psychological cultural proximity 4 & .287 & .748 & .191 & .227 \\
\hline Psychological cultural proximity 5 & .129 & .708 & .237 & .352 \\
\hline Attachment to Korean Wave stars 1 & .153 & .354 & .764 & .054 \\
\hline Attachment to Korean Wave stars 2 & .147 & .182 & .840 & .175 \\
\hline Attachment to Korean Wave stars 3 & .071 & .176 & .849 & .199 \\
\hline Attachment to Korean Wave stars 4 & .114 & .214 & .782 & .206 \\
\hline Purchase intention 1 & .139 & .232 & .062 & .797 \\
\hline Purchase intention 2 & .202 & .122 & .172 & .809 \\
\hline Purchase intention 3 & .250 & .164 & .260 & .687 \\
\hline Purchase intention 4 & .238 & .242 & .178 & .702 \\
\hline Eigen value & 3.665 & 3.407 & 3.174 & 2.915 \\
\hline Variance (\%) & 20.363 & 18.927 & 17.633 & 16.196 \\
\hline Cumulative variance (\%) & 20.363 & 39.290 & 56.923 & 73.119 \\
\hline Cronbach'a & .889 & .911 & .894 & .840 \\
\hline
\end{tabular}

Table 2. Descriptive statistics and correlation coefficients

\begin{tabular}{|c|c|c|c|c|c|c|c|}
\hline Variable & (1) & (2) & (3) & (4) & (5) & (6) & (7) \\
\hline (1) Purchase intention & 1 & & & & & & \\
\hline (2) Gender & $.135^{*}$ & 1 & & & & & \\
\hline (3) Age & .086 & .110 & 1 & & & & \\
\hline (4) Period of stay in Korea & $.225^{* *}$ & .070 & $.260^{* *}$ & 1 & & & \\
\hline (5) Attachment to Korean Wave stars & $.450^{* *}$ & $.159^{*}$ & .004 & .080 & 1 & & \\
\hline (6) Experiential cultural proximity & $.545^{* *}$ & -.018 & .096 & $.463^{* *}$ & $.376^{* *}$ & 1 & \\
\hline (7) Psychological cultural proximity & $.555^{* *}$ & .064 & .093 & $.210^{*}$ & $.588^{* *}$ & $.577^{* *}$ & 1 \\
\hline Min & 1 & 0 & 17 & 0 & 1 & 1 & 1 \\
\hline Max & 5 & 1 & 63 & 15 & 5 & 5 & 5 \\
\hline Mean & 3.221 & .570 & 28.570 & 1.580 & 2.794 & 2.970 & 3.280 \\
\hline$S D$ & .704 & .496 & 8.801 & 3.695 & .890 & 1.058 & .844 \\
\hline
\end{tabular}

Note. $S D$, standard deviation.

${ }^{*} p<.05,{ }^{* *} p<.01$ (two-tailed tests).

stay in Korea $(p<.005)$ had a significant positive effect on the purchase intention of Korean products. Model 2 is the result of regression analysis that verified the influence of attachment to Korean Wave stars. As can be seen in Model 2, it was found that the attachment to Korean Wave stars $(p<.001)$ had a significant positive effect on the purchase intention of Korean products. Therefore, Hypothesis 1, which predicted that an attachment to Korean Wave stars would have a positive effect on the purchase intention of Korean products, was supported. Model 3 is the result of regression analysis including psychological cultural 
Table 3. Results of regression analysis

\begin{tabular}{|c|c|c|c|c|c|c|}
\hline \multirow[t]{2}{*}{ Variable } & & \multicolumn{5}{|c|}{ Purchase intention } \\
\hline & & Model 1 & Model 2 & Model 3 & Model 4 & Model 5 \\
\hline \multirow[t]{3}{*}{ Control variables } & Gender & $\begin{array}{c}.081 \\
(.992)\end{array}$ & $\begin{array}{l}-.002 \\
(-.022)\end{array}$ & $\begin{array}{c}.057 \\
(.783)\end{array}$ & $\begin{array}{c}.108 \\
(1.481)\end{array}$ & $\begin{array}{c}.046 \\
(.645)\end{array}$ \\
\hline & Age & $\begin{array}{c}.025 \\
(.297)\end{array}$ & $\begin{array}{c}.058 \\
(.755)\end{array}$ & $\begin{array}{l}-.007 \\
(-.090)\end{array}$ & $\begin{array}{c}.071 \\
(.944)\end{array}$ & $\begin{array}{c}.054 \\
(.740)\end{array}$ \\
\hline & Period of stay in Korea & $\begin{array}{c}.212^{*} \\
(2.513)\end{array}$ & $\begin{array}{c}.175^{*} \\
(2.287)\end{array}$ & $\begin{array}{c}.127^{\dagger} \\
(1.652)\end{array}$ & $\begin{array}{l}-.035 \\
(-.407)\end{array}$ & $\begin{array}{c}.015 \\
(.182)\end{array}$ \\
\hline \multirow[t]{3}{*}{ Dependent variable } & Attachment to Korean Wave stars & & $\begin{array}{l}.438^{* * * *} \\
(5.835)\end{array}$ & & & $\begin{array}{c}.215^{*} \\
(2.468)\end{array}$ \\
\hline & Psychological cultural proximity & & & $\begin{array}{l}.456^{* * *} \\
(6.109)\end{array}$ & & $\begin{array}{c}.199^{*} \\
(2.165)\end{array}$ \\
\hline & Experiential cultural proximity & & & & $\begin{array}{l}.504^{* * * *} \\
(6.092)\end{array}$ & $\begin{array}{l}.289^{* *} \\
(3.116)\end{array}$ \\
\hline $\mathrm{R}^{2}$ & & .058 & .241 & .255 & .254 & .346 \\
\hline Adjusted $\mathrm{R}^{2}$ & & .038 & .219 & .234 & .233 & .318 \\
\hline$\triangle R^{2}$ & & & .183 & 0.197 & 0.196 & 0.288 \\
\hline$F$-value & & $2.894^{*}$ & $11.188^{* * *}$ & $12.056^{* * *}$ & $12.002^{* * *}$ & $12.260^{* * *}$ \\
\hline
\end{tabular}

Note. Standard coefficients are shown with $t$-value in parentheses.

${ }^{\dagger} p<.1,{ }^{*} p<.05,{ }^{* *} p<.01,{ }^{* * *} p<.001$ (two-tailed tests).

proximity. As can be seen in Model 3, psychological cultural proximity $(p<.001)$ was found to have a significantly positive effect on the purchase intention of Korean products. Therefore, Hypothesis 2 was supported that psychological cultural proximity would have a positive effect on purchase intention of Korean products. Model 4 is the result of regression analysis including experiential cultural proximity. As a result of regression analysis, it was found that experiential cultural proximity $(p<.001)$ had a significant positive effect on the purchase intention of Korean products, supporting Hypothesis 3 was supported. Finally, Model 5 presents the results of regression analysis including all variables used in this study. As can be seen in Model 5, all the independent variables were found to have a significant positive effect on the purchase intention of Korean products, showing consistent results with the results from Models 2 to 4 .

\section{Discussion}

The results of an empirical analysis of the effects of attachment to Korean Wave stars, psychological, and experiential cultural proximity on the purchase intention of Korean products are as follows.

First, it was found that the attachment to Korean Wave stars had a significant positive effect on the purchase intention of Korean products. Attachment to Korean Wave stars allows Chinese consumers to feel intimacy and emotional attachment to Korean Wave stars (Jeong \& Lee, 2016; Obst \& White, 2005; Thomson, 2006). Consistent with previous studies, these results suggest that consumers with a high attachment to Korean Wave stars identify themselves with their stars (Jeong \& Lee, 2016; Obst \& White, 2005; Thomson, 2006), and they have a desire to purchase products used by stars, which can increase their intention to purchase Korean products (Kleine III et al., 1993; Malär et al., 2011; Thomson et al., 2005).

Second, it was found that psychological cultural proximity had a significant positive effect on the purchase intention of Korean products. These results suggest that psychological cultural proximity, as previous studies emphasize, can increase good feeling for Korean products and form emotional attachment, positively affecting the intention to purchase Korean products (Jiang \& Wang, 2006; Mirabi et al., 2015; Kim et al., 2014).

Finally, it was found that experiential cultural proximity had a significant positive effect on the purchase intention of Korean products. These results can be confirmed to be consistent with the results of previous studies that experiential cultural proximity enhances a positive image of Korea and positively affects the purchase intention of Korean products due to the halo effect (Lee et al., 2017).

This study presents the following implications. First, in this study, a comprehensive study was conducted to establish attachment to Korean Wave stars and psychological and experiential cultural proximity as major independent variables in purchase 
intention of Korean products and to investigate the relationship between them. Although some previous studies analyzed the relationship between attachment to Korean Wave stars and purchase intention of Korean products (Hwang \& Park, 2021; Kim \& Lee, 2019) or investigated the relationship between psychological and experiential cultural proximity and purchase intention of Korean products (Wang \& Lee, 2019), no research has been attempted to investigate the relationship between purchase intention of Korean products in consideration of both attachment to Korean Wave stars, psychological and experiential cultural proximity. This study can make a meaningful academic contribution to the international marketing field because it presents the analysis results that attachment to Korean Wave stars, psychological and experiential cultural proximity positively affects the intention to purchase Korean products even in the COVID-19 pandemic era.

Second, the results of this study will be able to provide meaningful practical implications for Korean companies that need to formulate and implement marketing strategies for Chinese consumers. Despite the difficulty of normal consumption of the Korean Wave due to various regulations in Chinese government and pandemic of COVID-19, it was found that attachment to Korean Wave stars and psychological and experiential cultural proximity had positive effects on the purchase intention of Korean products. These results suggest that the attachment to Korean Wave stars, psychological and experiential cultural proximity are important antecedents of the purchase intention of Korean products (Boldero \& Francis, 2002; Jiang \& Wang, 2006; Kim et al., 2014; Lee et al., 2017; Zhou \& Lee, 2021).

This study also has the following limitations. First, since the survey was conducted in all regions in China, the unique characteristics of each region in China were not sufficiently reflected in the research model. Since China covers a large area, there may be differences in consumer characteristics between regions (Lee et al., 2017). Therefore, in future studies, it is necessary to establish a research model that sufficiently reflects the unique characteristics of each region in China. Second, since the sample size was not large, it was somewhat difficult to generalize the research results. Therefore, in future studies, it is necessary to increase the size of the sample in order to generalize the research results. Finally, despite the fact that there were various preceding factors that could affect the purchase intention of Korean products such as country image, corporate image and satisfaction with Korean Wave contents, these factors were not sufficiently controlled in this research model. In future studies, it will be necessary to include various variables as control variables that may affect the purchase intention of Korean products in the research model.

\section{Conclusion}

This study has useful theoretical implications in that it sets attachment to Korean Wave stars and psychological and experiential cultural proximity, which have not been examined by previous studies, as major independent variables in the purchase intention of Korean products and investigates the relationship between them. Additionally, despite the difficulty of normal consumption of the Korean Wave due to various regulations set by the Chinese government and the COVID-19 pandemic, it was found that attachment to Korean Wave stars and psychological and experiential cultural proximity had positive effects on the purchase intention of Korean products. These results suggest that the attachment to Korean Wave stars and psychological and experiential cultural proximity are important antecedents of the purchase intention of Korean products. Therefore, the results of this study will be able to provide meaningful practical implications for Korean companies that need to formulate and implement marketing strategies for Chinese consumers.

\section{References}

Ajzen, I., \& Fishbein, M. (1977). Attitude-behavior relations: A theoretical analysis and review of empirical research. Psychological Bulletin, 84(5), 888-918.

Augusta, E. D., Mardhiyah, D., \& Widiastuti, T. (2019). Effect of country of origin image, product knowledge, brand familiarity to purchase intention Korean cosmetics with information seeking as a mediator variable: Indonesian women's perspective. Dermatology Reports, 11(s1), 8014.

Bae, J. M., \& Lee, C. S. (2018). Suggestions for Korea's corporate image, product image, and purchase intention with consumer hostility: Focusing on Korean wave and satisfaction variables. East Asian Journal of Business Economics, 6(4), 25-34.

Boldero, J., \& Francis, J. (2002). Goals, standards, and the self: Reference values serving different functions. Personality and Social Psychology Review, 6(3), 232-241.

Chang, T. Z., \& Wildt, A. R. (1994). Price, product information, and purchase intention: An empirical study. Journal of the Academy of Marketing Science, 22(1), 16-27.

Chatterjee, S., \& Hadi, A. S. (2006). Regression analysis by example. Hoboken, NJ: John Wiley \& Sons.

Cole, T., \& Leets, L. (1999). Attachment styles and intimate television viewing: Insecurely forming relationships in a parasocial way. Journal of Social and Personal Relationships, 16(4), 495-511.

Cyrus, T. L. (2012). Cultural distance and bilateral trade. Global Economy Journal, 12(4), 1850275. 
Elasmar, M. G. (2014). The impact of international television: A paradigm shift. New York, NY: Routledge.

Erdem, S. A., \& Swift, C. O. (1998). Items to consider for just-intime use in marketing channels: Toward a development of a decision tool. Industrial Marketing Management, 27(1), 21-29.

Felbermayr, G. J., \& Toubal, F. (2010). Cultural proximity and trade. European Economic Review, 54(2), 279-293.

Fournier, S. (1998). Consumers and their brands: Developing relationship theory in consumer research. Journal of Consumer Research, 24(4), 343-373.

Georgiou, M. (2012). Watching soap opera in the diaspora: Cultural proximity or critical proximity? Ethnic and Racial Studies, 35(5), 868-887.

Giles, D. C., \& Maltby, J. (2004). The role of media figures in adolescent development: Relations between autonomy, attachment, and interest in celebrities. Personality and Individual Differences, 36(4), 813-822.

Greenwood, D. N., \& Long, C. R. (2011). Attachment, belongingness needs, and relationship status predict imagined intimacy with media figures. Communication Research, 38(2), 278-297.

Hair, J. F., Anderson, R. E., Tatham, R. L., \& Black, W. C. (1998). Multivariate data analysis. Upper Saddle River, NJ: Prentice Hall.

Hwang, J., \& Park, M. (2021). The effects of idol human brand's characteristics on consumer's idol human brand attachment, desire to imitate, desire to identify, and purchase intention. Fashion \& Textile Research Journal, 23(5), 559-575.

Ilicic, J., \& Webster, C. M. (2009). Exploring dimensions of consumer-human brand attachment. Paper presented at the Australian and New Zealand Marketing Academy Conference, Melbourne, Australia.

Jang, Y. S., \& Kim, S. H. (2018). The effects of national image and image of Korean foods on the vietnamese consumer's purchase intention: Focusing on moderating effect of Korean wave. Korean Journal of Food Marketing Economics, 35(1), 1-25.

Jeong, G. Y., \& Lee, S. H. (2016). A study on the effect of Chinese consumers' attachment toward Korean Hallyu stars on the authenticity and trust of Korean cosmetic brands. Korea Trade Review, 41(4), 185-219.

Jiang, Y., \& Wang, C. L. (2006). The impact of affect on service quality and satisfaction: The moderation of service contexts. Journal of Services Marketing, 20(4), 211-218.

Joseph, F. H. Jr., William, C. B., Barry, J. B., \& Rolph, E. A. (1998). Multivariate data analysis (5th ed.). Hampshire, UK: Cengage.

Khan, I., \& Rahman, Z. (2014). Influence of experiential marketing on customer purchase intention: A study of passenger car market. Management and Labour Studies, 39(3), 319-328.

Kowalczyk, C. M., \& Pounders, K. R. (2016). Transforming celebrities through social media: The role of authenticity and emotional at- tachment. Journal of Product \& Brand Management, 25(4), 345-356.

Kim, C. K., Jun, M. N., Kim, M. Y., \& Han, J. S. (2010). Strong attachment toward human brand: Its antecedents and implication for the quality of life. Journal of Consumer Studies, 21(4), 241-275.

Kim, E., \& Lee, J. H. (2019). Influence of characteristics, attachment and self congruity of Korean wave human brand on brand equity: Focused on Chinese female consumers. The Research Journal of the Costume Culture, 27(5), 479-495.

Kim, J. Y., \& Ahn, K. M. (2012). How Chinese population's preference to Korean wave contents does influence their intent to purchase Korean product, visit Korea and learn Hangul. The Journal of the Korea Contents Association, 12(5), 447-458.

Kim, S. M., \& Park, M. J. (2020). Evaluation of cross-national global market segmentation and strategy: The case of Korean wave for ASEAN countries. Asia Pacific Management Review, 25(4), 207-215.

Kim, Y. M., Kireyeva, A. A., \& Youn, M. K. (2014). Effects of SNS characteristics upon consumers' awareness, purchase intention, and recommendation. The Journal of Industrial Distribution \& Business, 5(1), 27-37.

Kleine, R. E., III, Kleine, S. S., \& Kernan, J. B. (1993). Mundane consumption and the self: A social-identity perspective. Journal of Consumer Psychology, 2(3), 209-235.

Lee, H., \& Jeong, G. (2016). A study on the effect of Hallyu stars as advertisement models of Korean cosmetics brands on Hallyu stars attachment and brand authenticity: Focused on Chinese consumers. International Area Studies, 20(2), 141-172.

Lee, H. S., \& Lee, H. (2012). Influence of SNS digital characteristics on cultural contents purchase intention. The Journal of the Korea Contents Association, 12(7), 336-345.

Lee, J., Kang, J. W., \& Lee, S. H. (2017). The effects of Korean wave experience type on Chinese residents' intention to visit Korea: Focusing on the moderating effect of national image. Journal of China Studies, 20(3), 101-119.

Lu, J., Liu, X., \& Cheng, Y. (2019). Cultural proximity and genre proximity: How do Chinese viewers enjoy American and Korean TV dramas? SAGE Open, 9(1), 2158244018825027.

Malär, L., Krohmer, H., Hoyer, W. D., \& Nyffenegger, B. (2011). Emotional brand attachment and brand personality: The relative importance of the actual and the ideal self. Journal of Marketing, 75(4), 35-52.

Mirabi, V., Akbariyeh, H., \& Tahmasebifard, H. (2015). A study of factors affecting on customers purchase intention. Journal of Multidisciplinary Engineering Science and Technology, 2(1), 267-273.

Nann, K., \& Park, J. K. (2016). The effect of consumption values of Korean cosmetics and country image of Korea on attitude and purchase intention in Myanmar: The moderating effect of Korean wave. Korean Journal of Business Administration, 29(9), 1461-1482. Nasermoadeli, A., Ling, K., \& Maghnati, F. (2013). Evaluating the 
impacts of customer experience on purchase intention. International Journal of Business and Management, 8(6), 128-138.

Natalia, U., \& Rizan, M. (2021). The influence of celebrity endorser toward emotional attachment and brand trust that impact to purchase intention. Jurnal Dinamika Manajemen dan Bisnis, $4(2), 1-20$

Ng, C. S. P. (2013). Intention to purchase on social commerce websites across cultures: A cross-regional study. Information \& Management, 50(8), 609-620.

Nunnally, J. C. (1978). Psychometric theory. New York, NY: McGraw-Hill.

Obst, P. L., \& White, K. M. (2005). An exploration of the interplay between psychological sense of community, social identification and salience. Journal of Community \& Applied Social Psychology, 15(2), 127-135.

Ohanian, R. (1990). Construction and validation of a scale to measure celebrity endorsers' perceived expertise, trustworthiness, and attractiveness. Journal of Advertising, 19(3), 39-52.

Park, C. W., MacInnis, D. J., Priester, J., Eisingerich, A. B., \& Iacobucci, D. (2010). Brand attachment and brand attitude strength: Conceptual and empirical differentiation of two critical brand equity drivers. Journal of Marketing, 74(6), 1-17.

Rabbanee, F. K., Roy, R., \& Spence, M. T. (2020). Factors affecting consumer engagement on online social networks: Self-congruity, brand attachment, and self-extension tendency. European Journal of Marketing, 54(6), 1407-1431.

Saleem, A., Ghafar, A., Ibrahim, M., Yousuf, M., \& Ahmed, N. (2015). Product perceived quality and purchase intention with consumer satisfaction. Global Journal of Management and Business Research, 15(1), 21-28.

Schmitt, B. (1999). Experiential marketing: How to get customers to sense, feel, think, act, and relate to your company and brands. New York, NY: Free Press.

Shah, S. S. H., Aziz, J., Jaffari, A., Waris, S., Ejaz, W., Fatima, M., \& Sherazi, S. K. (2012). The impact of brands on consumer purchase intentions. Asian Journal of Business Management, 4(2), 105-110.

Shen, J., \& Kim, M. S. (2018). The impact of the Hallyu fandom on Chinese consumers' purchase intention, satisfaction on Korean production and intention to visit Korea. The Journal of Modern China Studies, 20(1), 183-212.

Straubhaar, J. D. (1991). Beyond media imperialism: Assymetrical interdependence and cultural proximity. Critical Studies in Mass Communication, 8(1), 39-59.

Taylor, S. A., \& Baker, T. L. (1994). An assessment of the relationship between service quality and customer satisfaction in the formation of consumers' purchase intentions. Journal of Retailing, $70(2), 163-178$.
Thomson, M. (2006). Human brands: Investigating antecedents to consumers' strong attachments to celebrities. Journal of Marketing, 70(3), 104-119.

Thomson, M., MacInnis, D. J., \& Park, C. W. (2005). The ties that bind: Measuring the strength of consumers' emotional attachments to brands. Journal of Consumer Psychology, 15(1), 77-91.

Tjoe, F. Z., \& Kim, K. T. (2016). The effect of Korean wave on consumer's purchase intention of Korean cosmetic products in Indonesia. Journal of Distribution Science, 14(9), 65-72.

Vuong, B. N., \& Giao, H. N. K. (2020). The impact of perceived brand globalness on consumers' purchase intention and the moderating role of consumer ethnocentrism: An evidence from Vietnam. Journal of International Consumer Marketing, 32(1), 47-68.

Wakefield, K. L., \& Blodgett, J. G. (1999). Customer response to intangible and tangible service factors. Psychology \& Marketing, 16(1), 51-68.

Wang, L., \& Lee, J. H. (2019). The effect of K-beauty SNS influencer on Chinese consumers' acceptance intention of new products: Focused on elaboration likelihood model (ELM). Fashion \& Textile Research Journal, 21(5), 574-585.

Wang, X., \& Yang, Z. (2010). The effect of brand credibility on consumers' brand purchase intention in emerging economies: The moderating role of brand awareness and brand image. Journal of Global Marketing, 23(3), 177-188.

Yang, H., Jin, B. E., \& Jung, M. (2020). The influence of country image, the Korean wave, and website characteristics on cross-border online shopping intentions for Korean cosmetics: Focusing on US and Chinese consumers. International Journal of Costume and Fashion, 20(2), 38-49.

Yang, Y. S., \& Lee, J. E. (2020). The influence of Chinese consumers' experience of K-contents on purchase intention of made-in Korean products. International Commerce and Information Review, 22(4), 333-351.

Yang, Z. Y., \& He, L. Y. (2011). Goal, customer experience and purchase intention in a retail context in China: An empirical study. African Journal of Business Management, 5(16), 6738-6746.

Yu, H. C., \& Yu, L. B. (2020). Influence of Korean celebrity endorsement on Chinese consumers' purchase intention towards fashion goods. Journal of Fashion Business, 24(6), 148-158.

Zhang, J. Y., Park, J. O., \& Lee, J. Y. (2015). Effect of Chinese consumer's cultural proximity on country image and fashion product image of Korea. Journal of the Korea Fashion and Costume Design Association, 17(2), 173-184.

Zhou, W., \& Lee, J. S. (2021). The impact of attitude towards Korean wave of Chinese people on country image and intention to visit after Korean wave ban. Journal of Hospitality and Tourism Studies, 23(3), 141-156. 